\title{
Extended evaluation of quality of swimming pool water - importance of selected pollutant fractions
}

\author{
Edyta Laskawiec $^{1, *}$, Mariusz Dudziak ${ }^{1}$, and Joanna Wyczarska-Kokot ${ }^{1}$ \\ ${ }^{1}$ Institiute of Water and Wastewater Technology, Silesian University of Technology, Konarskiego 18, \\ 44-100 Gliwice, Poland
}

\begin{abstract}
The authors of the study attempted to determine the fraction of selected impurities in the filter backwash water from the pool circuit (hot tub). Ultrafiltration membranes were used for the separation process. The main parameter informing about the content of impurities in a given fraction was total carbon (including the total organic carbon). In the studies, fractions with the following sizes of $>200 \mathrm{kDa}, 50-200 \mathrm{kDa},<50 \mathrm{kDa}$ were separated. The fraction distribution in $>5 \mathrm{kDa}$ and $<5 \mathrm{kDa}$ was also analyzed. The percentage content of inorganic carbon and total organic carbon changed depending on the ultrafiltration membrane with different distribution characteristics. The concentration of total organic carbon decreased gradually with a decrease in the MWCO value of the membrane. On the basis of the total carbon value, it was found that the tested washings contained: $30.40 \mathrm{wt} . \%$ of $>200 \mathrm{kDa}$ fraction, $55.62 \mathrm{wt} . \%$ of fraction in the range of $50-200 \mathrm{kDa}$ and $13.98 \mathrm{wt} . \%$ of fraction $<50 \mathrm{kDa}$.
\end{abstract}

\section{Introduction}

Effectiveness of the filtration process, including the frequency and intensity of washing of the filtration equipment, has a big impact on the quality of water in swimming pools. The purpose of the process of washing of filtration beds is to restore their water treatment effectiveness. It is also performed to remove the pollutants collected in filtration beds, including floccules and sediments after coagulation process. During this process, a stream of wastewater - washings - is produced, which contains a large quantity of suspended solids and a number of pollutants with different molar masses and sizes, including disinfection byproducts (DBP's). Concentration of organic matter in the washings focuses most of all on particles with crossing the size of $45 \mu \mathrm{m}$ [1]. However, a large proportion of the $30 \mu \mathrm{m}$ fraction was noted, as well as that of nanoparticles with the size of approx. $955 \mathrm{~nm}$ [2]. The washings may be treated as a water stream that illustrates the entire range of pollutant fractions with different sizes and properties, that are contained in swimming pool water.

One must keep in mind that the process of filtration using filtration beds with granular filling is not fully selective. It is estimated that in the course of the filtration process approx. $30 \mathrm{wt} . \%$ of organic pollutants are washed out into the treated swimming pool water [3]. This problem applies in particular to pollutants with the smallest size/molar mass. A large quantity

\footnotetext{
*Corresponding author: edyta.laskawiec@polsl.pl
} 
of disinfection byproducts in swimming pool water has molar mass below 1,000 $\mathrm{m} / \mathrm{mol}$ [4]. Low molar mass is associated with a higher probability of infiltration of those compounds into the bodies of swimming pool users. An analysis of the proportion of the pollutant fractions in swimming pool water is particularly important from the point of view of their genotoxic properties which increase with decreasing molar mass [4, 5]. The highest genotoxicity is observed in the case of compounds with the molar mass below $200 \mu \mathrm{g} / \mathrm{mol}$ [4]. For example Glauner et al. [6] in own work defined the proportion of the $>1,000 \mathrm{~g} / \mathrm{mol}$ fraction as equal to $14 \mathrm{wt} . \%$, the proportion of the $200-1,000 \mathrm{~g} / \mathrm{mol}$ fraction as equal to $54 \mathrm{wt} . \%$, and the proportion of the $<200 \mathrm{~g} / \mathrm{mol}$ fraction as equal to $32 \mathrm{wt} . \%$.

What is particularly important from the point of view of evaluation of the quality of swimming pool water is the concentration of carbon compounds, specified as the concentration of total organic carbon (TOC). The TOC parameter is highly correlated to the concentration of DBP's in samples of water that was subject to chlorination processes [4, 7]. Therefore, this parameter may provide information on the proportion of chemical compounds from this group in the washings samples.

The objective of the study was to evaluate the quality of washings, to determine the proportion of selected pollutant fractions using the value of the concentration of total carbon (TC), total organic carbon (TOC), and inorganic carbon (IC) in the samples. Fractioning was performed using ultrafiltration membranes with different ranges of particle separation. The changes in the concentration of carbon compounds in the permeates produced after the membrane processes were presented. The percentage of pollutants in the following ranges was determined: $>200 \mathrm{kDa}, 200-50 \mathrm{kDa}$, and $<50 \mathrm{kDa}$. Also, the changes of the IC and TOC concentration were determined in the feed, the permeate, and the retentate in a selected UF process and the self-treatment ability of washings in the gravity settling process was identified.

\section{Methods}

\subsection{Physicochemical analysis}

The evaluation of the tested washings was performed based on selected physicochemical parameters. The conductivity, the reaction $(\mathrm{pH})$, and the redox potential of the samples were measured with the inoLab ${ }^{\circledR} 740$ (WTW, Pomiarowy i Analityczny Sprzęt Techniczny) multiparameter meter. Ultraviolet absorbance, at the wavelength of $254 \mathrm{~nm}$, was measured using the UV VIS Cecil 1000 made by Analytik Jena AG, with the optical path length of the cuvette $\mathrm{d}$ equal to $1 \mathrm{~cm}$. The $\mathrm{UV}_{254}$ value was determined using the measurement method presented by US EPA [8], and the final result of the analysis is presented in $\mathrm{m}^{-1}$. The turbidity of the samples was determined using the EUTECH Instruments TN-100 turbidimeter. The total chlorine concentration (total and free) was performed using the calorimetric method in situ using the portable $\mathrm{Hach}^{\circledR}$ Pocket Colorimeter ${ }^{\mathrm{TM}}$ II device. The total hardness was determined using the EDTA method and the concentration of chlorides was determined using the argentometric method. The total carbon, inorganic carbon, organic carbon, and dissolved carbon (DOC) (after filtration, pore size $0.45 \mu \mathrm{m}$ ) were determined using the TOC-L series analyzer using the method of catalytic oxidation by combustion at the temperature of $680^{\circ} \mathrm{C}$ (Shimadzu). The values of the remaining parameters and indicators (free chlorine, total chlorine, potassium, nitrate, ammonium nitrogen, total nitrogen, sulfate, chemical oxygen demand, cyanuric acid, phenol index, aluminum) were determined using the photometric method in cuvette tests, using the VIS Spectroquant ${ }^{\mathbb{R}}$ Pharo 300 UV spectrophotometer (Merck). Measurements of the parameters listed in table 1 were carried out once. 


\subsection{Evaluation of the settling ability of washings}

The settling ability of the tested washings was evaluated by way of a test in an Imhoff funnel (a 1 liter sample), with the process being observed for 12 hours. An increase in the volume of the sediment was observed after periods of 1, 2, 3, and 12 hours. Moreover, supernatant samples were taken to analyze their carbon concentration and their turbidity. The results presented show the arithmetic mean for three samples taken in identical conditions.

\subsection{The methods of fractioning of pollutants in the washings}

Fractioning of the pollutants in the raw washings was performed using flat ultrafiltration membranes made by Osmonics Inc. (USA), with a different separation range, i.e. the molecular weight cut-off (MWCO), and a different type of membrane-forming material. The selected process parameters are shown in Table 1.

Table 1. Characteristics of membranes and operating parameters of the process.

\begin{tabular}{|c|c|c|c|}
\hline $\begin{array}{c}\text { Membrane } \\
\text { symbol }\end{array}$ & Membrane material & $\begin{array}{c}\text { MWCO, } \\
\text { kDa }\end{array}$ & $\begin{array}{c}\text { Process pressure, } \\
\text { MPa }\end{array}$ \\
\hline YMV53001 & Polyvinylidene difluoride & 200 & 0.2 \\
\cline { 1 - 1 } \cline { 3 - 4 } YMBN3001 & (PVDF) & 50 & 0.2 \\
\hline YMPTSP3001 & Polyethersulfone (PES) & 5 & 0.2 \\
\hline
\end{tabular}

The membranes were placed in a steel filtration cell with the volume of 0.381 where the active surface of the membrane was equal to $0.00385 \mathrm{~m}^{2}$. Before the filtration started, the new membranes were conditioned by filtering deionized water in order to stabilize the volume of the permeate stream. The process was performed in a dead-end filtration layout until $50 \mathrm{wt} . \%$ of the feed volume was collected. During each filtration cycle, three samples with the volume of 0.051 were taken. Each completed ultrafiltration (UF) process included three filtration cycles, whereby after each cycle the membranes were washed with deionized water.

All the samples underwent an analysis of the concentrations of TC, TOC, IC, and DOC, and of turbidity. As a part of the study discussed herein, the arithmetic mean values that were determined and the variability of the results in the form of standard deviations (Microsoft Office Excel 2016) were presented.

\section{Results and discussion}

\subsection{Origin and quality of washings}

The washings used in the tests came from the process of washing of a multi-layer bed (activated carbon - quartz sand) with the diameter of 1,800 $\mathrm{mm}$. The pressure filter is located in the water treatment circuit of a hot tub. Water filtration is performed at the speed of $30 \mathrm{~m} / \mathrm{h}\left(24 \mathrm{~m}^{3} / \mathrm{h}\right)$ and the filtration bed is washed (with air and water) at the speed of $50 \mathrm{~m} / \mathrm{h}$ $\left(39 \mathrm{~m}^{3} / \mathrm{h}\right)$. In order to keep the filtration process effective, the filtration bed is washed every 48 hours. One washing requires approximately $15 \mathrm{~m}^{3}$ of water, which is taken from a compensating reservoir. Washings samples were taken during the washing cycle performed after the facility was closed. The physicochemical analyses were performed in the morning the following day. 
The values of selected physicochemical parameters and indicators of the washings are shown in Table 2. The washings that were sampled were characterized, most of all, by significant turbidity, which was equal to 7.71 NTU. Moreover, elevated concentrations of chlorides $\left(358.55 \mathrm{mg} \mathrm{Cl}^{-} / 1\right)$ and of aluminum $(0.86 \mathrm{mg} \mathrm{Al} / \mathrm{l})$ and an elevated redox potential were identified, which indicates that there is a problem with sanitization of the wastewater and the presence of numerous colonies of bacteria $(270 \mathrm{mV})$ [9].

Table 2. Characteristics of washings from a hot tub circuit.

\begin{tabular}{|c|c|c|}
\hline Parameter/Indicator & Unit & Value \\
\hline $\mathrm{pH}$ & - & 6.84 \\
\hline Conductivity & $\mu \mathrm{S} / \mathrm{cm}$ & 1143.10 \\
\hline Redox potential & $\mathrm{mV}$ & 270.00 \\
\hline Turbidity & NTU & 7.71 \\
\hline Absorbance $\left(\mathrm{UV}_{254}\right)$ & $\mathrm{m}^{-1}$ & 12.00 \\
\hline Free chlorine & $\mathrm{mgCl}_{2} / 1$ & 0.40 \\
\hline Total chlorine & $\mathrm{mgCl}_{2} / 1$ & 0.74 \\
\hline Potassium & $\mathrm{mgP} / 1$ & 4.70 \\
\hline Nitrate & $\mathrm{mgNO}_{3}{ }^{-} / 1$ & 2.80 \\
\hline Ammonium nitrogen & $\mathrm{mgN} \mathrm{NH}_{4} / \mathrm{l}$ & $<0.20$ \\
\hline Total nitrogen & $\mathrm{mgN} / 1$ & 7.00 \\
\hline Sulfate & $\mathrm{mgSO}_{4}^{2-} / 1$ & 96.00 \\
\hline Chemical oxygen demand (COD) & $\mathrm{mgO}_{2} / 1$ & $<15.00$ \\
\hline Cyanuric acid & $\mathrm{mgC}_{3} \mathrm{H}_{3} \mathrm{~N}_{3} \mathrm{O}_{3} / 1$ & 4.00 \\
\hline Phenol index & $\mathrm{mgC}_{6} \mathrm{H}_{6} \mathrm{O} / 1$ & 0.57 \\
\hline Total hardness & $\mathrm{mgCaCO}_{3} / 1$ & 88 \\
\hline Chloride & $\mathrm{mgCl}^{-} / 1$ & 358.55 \\
\hline Aluminum & $\mathrm{mgAl} / 1$ & 0.86 \\
\hline
\end{tabular}

From the standpoint of the intensity of use of water in the basin, it is important to analyze the concentration of total nitrogen, total organic carbon (TOC), and potassium [10]. It was found that the values of those parameters in the tested sample were not elevated. Values of these parameters were referred to the Polish Regulation of the Minister of the Environment, regarding the conditions to be met when introducing sewage into waters or to the ground, and 
on substances particularly harmful to the water environment (Journal of Laws of 2014, item 1800). The TOC concentration in the swimming pool water is in the range of 3.3 to $12.9 \mathrm{mg} \mathrm{C} / 1$ [4]. On the other hand, some authors specify that TOC concentration in chlorinated water is as high as in the range of 0.25 to $76 \mathrm{mg} / \mathrm{l}$, with a high correlation to the concentration of chloroform [11].

\subsection{Fractionation effects in the ultrafiltration process}

In the process of settling, it was found that the turbidity was reduced from 7.71 to $3.95 \mathrm{NTU}$ (Fig. 1), while the volume of the sludge increased from 0 to $2.7 \mathrm{~cm}^{3}$ (with a total sample volume of 1 liter). The use of the settling process in relation to the tested washings enabled reducing the turbidity by approx. $51 \mathrm{wt} . \%$. The remaining part of the suspension was composed of hardly settling particles. Moreover, it was found that the concentration of total carbon was reduced (by $0.25 \mathrm{mg} \mathrm{C} / 1$ relative to the initial value), while the concentration of IC increased by $0.117 \mathrm{mgC} / 1$ and the concentration of TOC decreased by $0.372 \mathrm{mg} \mathrm{C} / 1$. On the other hand, the differences in concentrations in tested samples can be considered as slight.

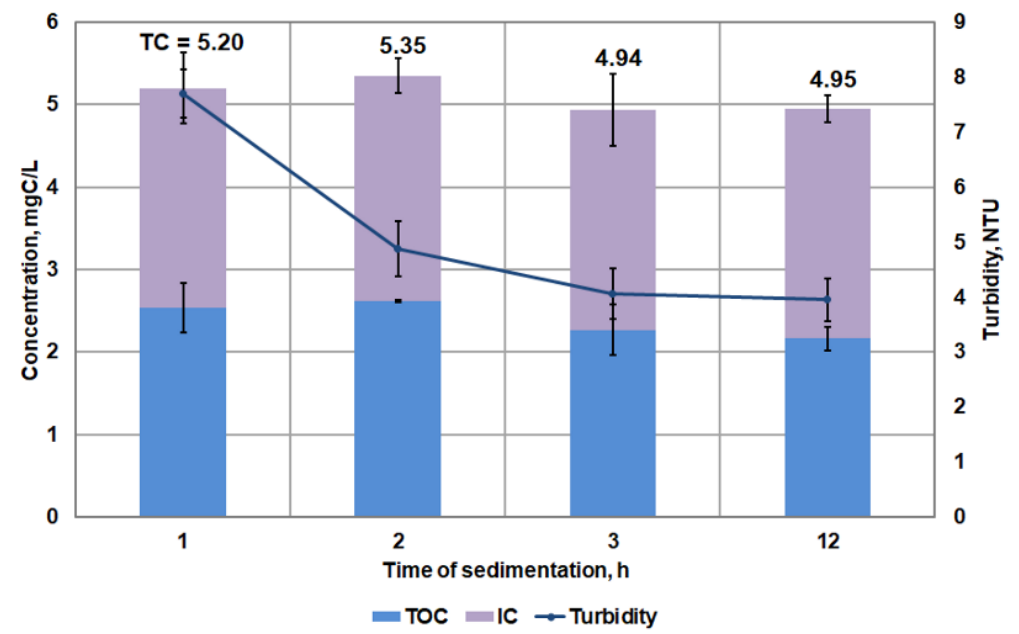

Fig. 1. A change of selected physicochemical parameters in the course of settling of suspensions in raw washings.

The process of ultrafiltration significantly reduced the turbidity of the washings. UF performed using a PVDF membrane with MWCO equal to $200 \mathrm{kDa}$ enabled achieving the average value on the level of 1.12 NTU. In the case of a membrane with MWCO equal to $50 \mathrm{kDa}$, turbidity was equal to 0.46 NTU. Figure 2 shows the values of carbon concentrations in the washings and in the permeates. The PVDF ultrafiltration membranes contributed to a reduction of the concentration of total organic carbon by $0.71 \mathrm{mg} \mathrm{C} / 1$ and $1.54 \mathrm{mg} \mathrm{C} / 1 \mathrm{in}$ the case of membranes with the MWCO value equal to $200 \mathrm{kDa}$ and $50 \mathrm{kDa}$, respectively. However, the membranes did not remove inorganic carbon. The membrane with a lower molar mass enabled a reduction of the concentration of dissolved organic carbon from $2.14 \mathrm{mg} \mathrm{C} / 1$ to $1.83 \mathrm{mg} \mathrm{C} / 1$. In the case of the YMV53001 membrane the DOC value did not change (2.14 $\mathrm{mg} \mathrm{C} / \mathrm{l})$. 


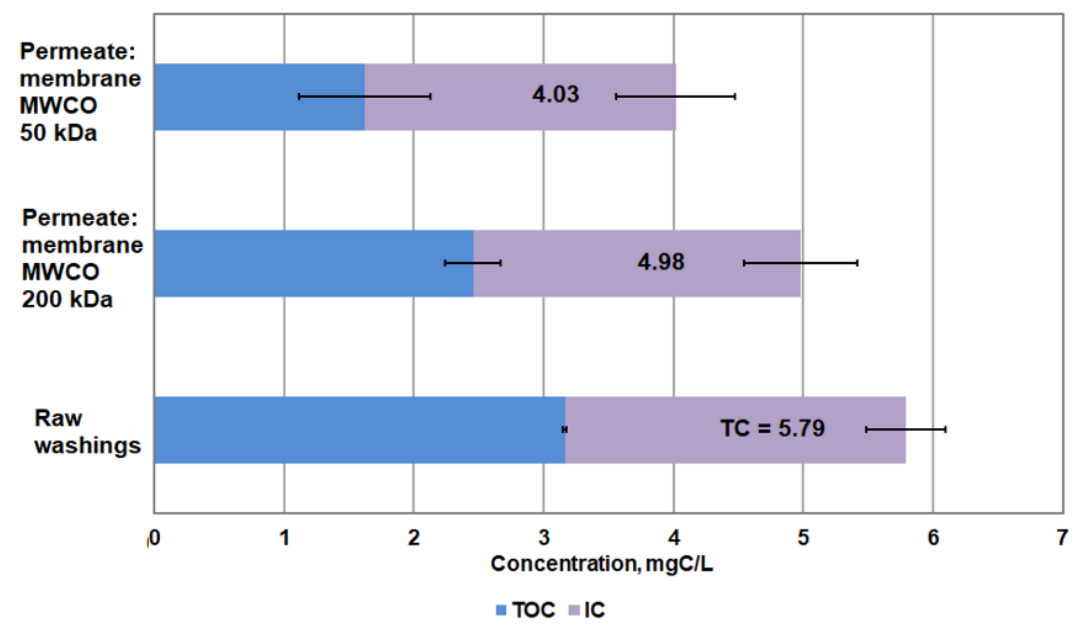

Fig. 2. Concentration of carbon in raw sample of washings and samples taken after ultrafiltration (PVDF membranes YMV53001 (200 kDa) and YMBN3001 (50 kDa)).

An analysis of the percentage content of IC and TOC in the permeates obtained in the process of ultrafiltration (Fig. 3) lead to the conclusion that the fraction of grain size above $200 \mathrm{kDa}$ contained approx. 49 wt.\% of organic carbon. The content of inorganic carbon increased in successive separated fractions as a result of removal of organic compounds. In the fraction containing particles of grain size below $50 \mathrm{kDa}$, the TOC was equal to $35.61 \mathrm{wt} . \%$.

On the other hand, an analysis of the TC values measured in raw washings and in permeates resulted in the conclusion that the fraction with the smallest grain size constituted about $14 \mathrm{wt} . \%$ of all carbon compounds in the tested sample. The fraction with grain size in the range of $50-200 \mathrm{kDa}$ constituted the largest percentage of total carbon in the tested washings samples (approx. $56 \mathrm{wt} . \%$ ).

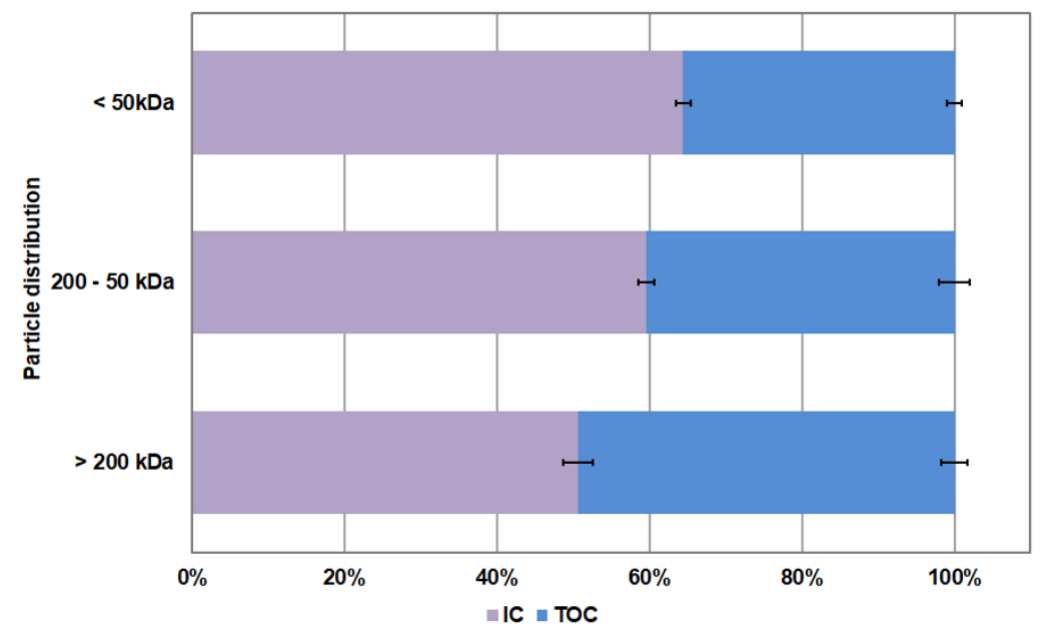

Fig. 3. Percentage content of inorganic and organic carbon fractions in permeates after ultrafiltration. 


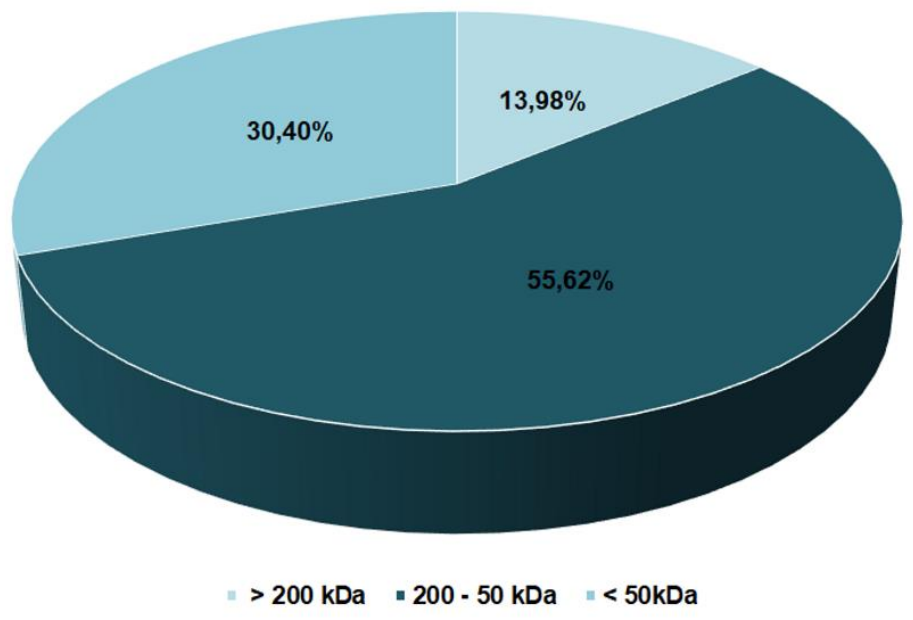

Fig. 4. Approximate percentage of pollutant fractions in the tested washings based on total carbon.

At the last stage of the study, the content of TOC and IC concentration in the fraction below $5 \mathrm{kDa}$, performed using a PES membrane (YMPTSP3001), was compared (Fig. 5). Before starting the filtration, the measurement of carbon concentration was again performed (TC in raw washings was $3.67 \mathrm{mg} / \mathrm{l}$ ). The reduction of the total carbon concentration was equal to approx. $67 \mathrm{wt} . \%$. The average value of turbidity of the permeate samples was equal to 0.39 NTU. What was also observed was an increase of carbon compounds in the retentate (in the case of filtration in a dead-end layout, it should be two-fold); the TC value was equal to $4.02 \mathrm{mg} \mathrm{C} / 1$. This value was mostly due to inorganic carbon. On the other hand, the TOC concentration in the retentate was lower than in raw washings by approx. $0.34 \mathrm{mg} \mathrm{C} / 1$. The turbidity of the retentate was equal to 12.41 NTU. When conducting the fractionation of raw washes using membranes, it should be borne in mind that high turbidity may contribute to blocking the pores of the membrane. For membranes with high MWCO values, the pore size may be reduced.

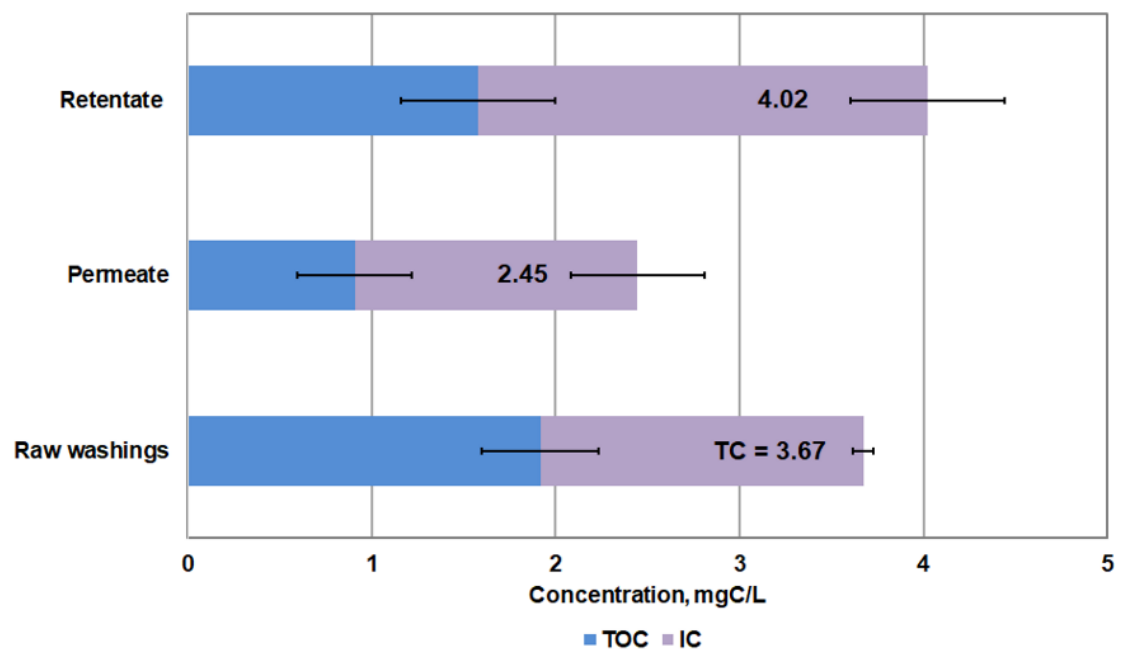

Fig. 5. Concentration of carbon in the raw washings and in the samples after ultrafiltration (PES membrane YMPTSP3001, MWCO = $5 \mathrm{kDa}$ ). 


\section{Conclusion}

Washings from swimming pool water circuits are characterized by a high content of turbidity. In the study discussed herein, $51 \mathrm{wt} \%$ of solid particles were well settling suspension. The settling process enabled a significant reduction of turbidity; however, it did not contribute to a reduction of carbon concentration in the washings and a reduction of concentration of organic pollutants.

The percentage content of inorganic carbon and total organic carbon changed depending on the ultrafiltration membrane with different distribution characteristics. The concentration of total organic carbon decreased gradually with a decrease in the MWCO value of the membrane. Moreover, it was found that the washings contained about $14 \mathrm{wt} . \%$ of compounds with the size of less than $50 \mathrm{kDa}$ and over $30 \mathrm{wt} . \%$ of compounds with the size of over 200 $\mathrm{kDa}$.

The process of ultrafiltration enables separating fractions of compounds with a wide range of sizes. On the other hand, from the standpoint of toxicological risk, it is also necessary to separate fractions of small-particle compounds with the grain size below $500 \mathrm{Da}$ in the process of nanofiltration [12]. One must keep in mind that the content of washings and swimming pool water differs depending on the purpose of the basin in the circuit, the intensity of use, and the effectiveness of the filtration bed.

Study conducted within the departmental research grant for young scientists (BKM- 554/RIE-4/17) "Extended Physicochemical Evaluation of Swimming Pool Water".

\section{References}

1. N.J. McCormick, M. Porter, M.E. Walsh, Water Res. 44, 4581-4589 (2010)

2. P. Wiercik, M. Domańska, Sci. Rev. Eng. Env. Sci. 54, 333-3443 (2011)

3. A. Korkosz, M. Janczarek, R. Aranowski, J. Rzechuła, J. Hupka, Physicochem. Probl. Miner. Process. 44, 103-113 (2010)

4. S. Chowdhury, K. Alhooshani, T. Karanfil, Water Res. 53, 68-109 (2014)

5. T.L.L. Teo, H.M. Coleman, S.J. Khan, Environ. Int. 76, 16-31 (2014)

6. T. Glauner, P. Waldmann, F.H. Frimmel, C. Zwiener, Water Res. 39, 18, 4494-502 (2005)

7. E. Righi, G. Fantuzzi, G. Predieri, G. Aggazzotti, Microchem J. 113, 23-29 (2014)

8. B. B. Poter, EPA Document, Method 415, 3 (2009)

9. J. Steininger, Swimming Pool Age \& Spa Merchandiser (1985)

10. J. De Laat, W. Feng, D. Adams Freyfer, F. Dossier-Berne, Water Res. 45, 1139-1146 (2011)

11. J. Leea, K-T. Hab, K-D. Zoha, Sci Total Environ. 407, 1990-1997 (2009)

12. X. Zhang, R.A. Minear, Env. Sci. Technol. 36, 19, 4033 (2002) 